\title{
Influence of patient characteristics on care time in patients hospitalized with schizophrenia
}

\author{
This article was published in the following Dove Press journal: \\ Neuropsychiatric Disease and Treatment \\ 25 August 2014 \\ Number of times this article has been viewed
}

\author{
Yukiko Sugibayashi' \\ Kimio Yoshimura' \\ Keita Yamauchi ${ }^{1,2}$ \\ Ataru Inagaki ${ }^{3}$ \\ Naoki Ikegami' \\ 'Department of Health Policy \\ and Management, Keio University \\ School of Medicine, Tokyo, ${ }^{2}$ Keio \\ University Graduate School of \\ Health Management, Kanagawa, \\ ${ }^{3}$ Aoyama Gakuin University, School \\ of International Politics, Economics \\ and Communication, Tokyo, Japan
}

Correspondence: Kimio Yoshimura

Department of Health Policy and Management, Keio University School of Medicine, 35 Shinanomachi, Shinjuku-ku, Tokyo, Japan

Tel +8133353 I 2 II

Fax +81332554828

Email kyoshimu@hpm.med.keio.ac.jp
Background: In the current Japanese payment system for the treatment of psychiatric inpatients, the length of hospital stay and nurse staffing levels are key determinants of the amount of payment. These factors do not fully reflect the costs of care for each patient. The objective of this study was to clarify the relationship between patient characteristics and their care costs as measured by "care time" for patients with schizophrenia.

Methods: Patient characteristics and care time were investigated in 14,557 inpatients in 102 psychiatric hospitals in Japan. Of these 14,557 inpatients, data for 8,379 with schizophrenia were analyzed using a tree-based model.

Results: The factor exerting the greatest influence on care time was "length of stay", so subjects were divided into 2 groups, a "short stay group" with length of stay $\leqq 104$ days, and "long stay group" $\geqq 105$ days. Each group was further subdivided according to dependence with regard to "activities of daily living", "psychomotor agitation", "verbal abuse", and "frequent demands/repetitive complaints", which were critical variables affecting care time. The mean care time was shorter in the long-stay group; however, in some long-stay patients, the mean care time was considerably longer than that in patients in the shortstay group.

Conclusion: The results of this study suggest that it is necessary to construct a new payment system reflecting not only length of stay and nurse staffing levels, but also individual patient characteristics.

Keywords: psychiatric hospital, schizophrenia, care time, case mix, tree-based model

\section{Introduction}

In Japan, over $90 \%$ of psychiatric inpatient care is provided by private sector hospitals, mostly owned by physicians, each averaging about 250 beds. The Japanese government has been attempting to decrease the number of psychiatric beds, which is currently the highest in the world, through the nationally uniform payment system by decreasing the daily rate for units with long-stay patients while increasing the rate for acute care units. It has also provided incentives for hospitals to increase nurse staffing levels by paying more for units that meet these levels. As a result, acute care units with high staffing levels are paid more than chronic care units that have low staffing levels.

While the current payment system may be generally appropriate, it does not take into consideration long-stay patients requiring relatively high levels of care, and consequently costing the hospital more than the amount paid. In order to care for these patients, other patients in the same unit might not receive the amount of care they need. This problem would be exacerbated in hospitals having both acute-stay and long-stay patients in the same unit because they are not able to meet the higher staffing levels required in acute units. 
A case-mix-based per diem payment system would resolve this problem. The algorithm for grouping patients is developed by statistically analyzing patient characteristics that best explain differences in cost. In psychiatric care, since labor costs account for approximately $60 \%$ of hospital expenditure and vary widely between patients, ${ }^{1}$ we decided to measure the "wage-weighted care time" that each patient receives, following the method developed by Schneider et $\mathrm{al}^{2}$ for nursing homes in the USA. By measuring the care time each patient receives from each category of staff and then weighing this time according to the relative wages of nurses, care staff, and others providing care, it is possible to calculate the relative costs accruing to each patient. Fries et $\mathrm{al}^{3}$ later conducted a study in Veterans Administration medical psychiatric centers, which included both acute and chronic patients. However, this study explained only $11.4 \%$ of the variability in per diem resource use. Other research ${ }^{4}$ has focused exclusively on acute patients or would not be relevant in the Japanese context.

Yamauchi ${ }^{5}$ undertook a preliminary study, conducted in 1994 and published in 1997, using the method developed by Schneider et. al. ${ }^{2}$ However, the sample size was relatively small and the results failed to convince the government and the Japan Psychiatric Hospitals Association of the need to adopt this new method of payment. Moreover, since Yamauchi's study $^{5}$ was conducted, the payment system has been revised seven times, and has generally tended to increase the difference between the better paid and better staffed acute care units and the less paid and less staffed chronic care units. In addition, the inpatient population has been aging, ${ }^{6}$ and second-generation antipsychotics are now more widely used.

For these reasons, we decided to conduct this study, which has a large sample size from over 100 hospitals. We focused our attention on patients with schizophrenia because grouping would have a more direct relationship with their clinical characteristics. These patients account for approximately $60 \%$ of all psychiatric hospital inpatients in Japan, many of whom stay in hospital for a long time. ${ }^{7}$

\section{Materials and methods Subjects}

This survey was conducted in 2009 with the cooperation of 102 psychiatric hospitals in Japan, including 90 private hospitals, five municipal hospitals, and seven national hospitals. In the two to three units selected from each hospital, all patients who were hospitalized at the time of the 24-hour survey period were investigated. Of a total of 14,557 patients, we analyzed data for 8,379 who were diagnosed as having schizophrenia (F20) according to the ICD-10 (Tenth Revision of the International Statistical Classification of Diseases and Related Health Problems). Special secure units for forensic psychiatry were not included in this study.

Since our objective lay in developing a case-mix-based grouping system for both acute and chronic units that could also be applied to units that have not yet been adequately differentiated, we chose psychiatric hospitals that would cover the full range. We then asked the hospitals to choose two or three units that had patients with a contrasting case-mix. Thus, the sites chosen do not constitute a representative cross-section of the inpatient psychiatric population in Japan. For example, a national sample would have a greater proportion of elderly patients receiving chronic care. This group would be undersampled in our study because they would essentially have the same characteristics. We also did not attempt to analyze regional differences because the payment system in Japan is uniformly set by the national government, which has led to a homogeneous pattern of delivering care throughout the country, ${ }^{6}$ including the poor development of community care.

Note that in Japan, nurse staffing levels across hospitals for each type of unit, ie, acute or chronic, are relatively homogeneous because the nationally uniform payment system sets payment based on acute or chronic designation and nurse staffing levels. The relative weight of staff other than nurses, such as psychologists, is low because the payment system does not explicitly reimburse their services.

\section{Measurement items}

\section{Total weighted care time (index of labor cost per patient-day)}

Time studies were conducted in each selected ward during the survey period (December 14-18, 2009, or January 18-22, 2010). For the unit staff, this was for a 24 -hour period given that their activities would not differ greatly on a day-to-day basis. For the nonunit staff, such as physicians, the time study survey period was 5 days. The time (minutes) spent attending to each patient was self-recorded using a stopwatch provided to each staff member. The care time included not only the time actually spent with the patient, but also such activities as writing up the patient's records and the time spent in conference devoted to that patient. After the care time was recorded by each staff member, the care time provided by all staff members during the observation period was calculated for each patient. For nonunit staff, their care time was divided by five and added to the unit staff time. Care time was measured in minutes per day.

In order to standardize differences in costs due to differences in wages between staff categories, we converted the 
actual care time to "wage-weighted care time" by weighting the care time against the average wage of a registered nurse as the baseline (1.0). The relative wage weights were taken from the Japan Psychiatric Hospitals Association General Survey Report for the 2007 fiscal year. ${ }^{8}$ Relative to registered nurses, the wage of psychiatrists was 2.28 ; licensed practical nurses 0.86 ; nurse aides 0.60 ; pharmacists 1.18 ; dietitians 0.71 ; clinical laboratory technologists 0.96 ; radiology technologists 1.12 ; psychiatric social workers 0.80 ; clinical psychologists 0.82 ; occupational therapists 0.90 ; and others 0.68 . Thus, the care time provided by each occupational category was multiplied by the above relative weights to calculate the total wage-weighted care time in minutes per day (hereafter referred to simply as "care time") for each patient.

Note that costs other than those measured above are likely to be either small or would be allocated equally between all patients on a per head basis, such as utility and maintenance costs, so they need not be considered for the purposes of developing a case-mix-based payment system.

\section{Patient characteristics}

Each patient was assessed for psychiatric symptoms, cognitive function, problem behavior, insight into disease, activities of daily living (ADL), and instrumental ADL, in addition to basic attributes and admission history. These assessments were made by the attending physician for each patient and by the head nurse of the unit.

\section{Oxford University version of the Brief Psychiatric Rating Scale}

The Brief Psychiatric Rating Scale (BPRS) consists of 18 items, and the attending physician rated each item on a seven-point scale of 0 (no symptoms), 1 (very mild), 2 (mild), 3 (moderate), 4 (somewhat severe), 5 (severe), to 6 (very severe). The version translated by Sumiyama and Kitamura, ${ }^{9}$ and Kitamura et $\mathrm{al}^{10}$ was used in this study. The interrater reliability of the Japanese version was confirmed by Kitamura et al. ${ }^{10}$

\section{Cognitive function}

Since a third of the patients were aged 65 years or over, cognitive impairment may have developed, which would have a significant effect on costs. We evaluated cognitive impairment on the basis of "short-term memory impairment", "cognitive ability", and "communication ability". 11,12

Nurses rated "short-term memory impairment" on a two-point scale ( 0 , without problems; 1 , with problems), "cognitive ability" on a four-point scale ( 0 , independent; 1 , some difficulty; 2 , need for watching; 3 , unable to judge), and "communication ability" on a four-point scale $(0$, able to communicate; 1 , some difficulty; 2 , limited to specific requests; 3 , unable to communicate).

\section{Problem behavior}

Problem behavior consisted of 18 items that had been developed by an expert panel of clinicians from the hospitals surveyed. The presence or absence of "self-injury", "suicide attempt", "intimidation", and "actual violence" during the previous 5 days was rated on a two-point scale $(0$, without problems; 1, with problems). Thirteen items, including "frequent demands/repetitive complaints" and "verbal abuse" (meaning that other patients could not rest because of the patient's voice) were rated as for frequency of occurrence on a four-point scale ( 0 , absent; 1 , present on 1 day; 2 , present on 2 days; 3 , present on all days) during a 3 -day period that included the day of the 24-hour time study by the nurses. The remaining item, ie, "self-injurious ideation, attempt/violent ideation, or violence to others", was rated on the day of the 24-hour time study by the attending physicians on a fourpoint scale ( 0 , no; 1 , little; 2 , moderate; 3 , high).

\section{Insight into disease}

Two items of insight into disease, ie, "recognition of need for medication" and "consciousness of disease", were assessed by the attending physicians; the former was rated on a fourpoint scale ("sufficient recognition", "insufficient recognition but compliant to medication", "insufficient recognition and occasional reluctance or refusal to take medication", "not prescribed") and the latter on a three-point scale (sufficient, insufficient, and little).

\section{Dependence in ADL}

ADL was rated by nurses using the same items as those employed by Fries et al in the RUG (the Resource Utilization Groups) version III case-mix grouping system ${ }^{13-15}$ : "mobility in bed", "transfer", "diet", "toileting", and "personal hygiene" were rated by nurses on a seven-point scale ( 0 , independent; 1 , preparation only; 2, observation; 3 , partial support; 4, extensive support; 5, maximum support; 6 , totally dependent).

\section{Dependence in independent ADL}

The seven items on the independent ADL scale, ie, abilities in "meal preparation", "ordinary housework", "managing finances", "managing medications", "phone use", "shopping", and "transportation" were rated by nurses on a threepoint scale ( 0 , no problems; 1 , some difficulty; 2 , much difficulty). 


\section{Presence of complications and medical treatment}

In the Survey on the Comprehensive Assessment of Chronic Hospital Care ${ }^{16}$ conducted by the Ministry of Health, Labour and Welfare in 2008, the presence of complications and medical treatments was recorded for 39 items. We excluded 18 items that would rarely occur in psychiatric hospitals, leaving 21 items that were rated as present or absent by the attending physicians.

\section{Statistical analysis}

The statistical method used to analyze the care time per patient-day was the classification and regression tree (CART), ${ }^{17}$ which has been widely used in developing payment systems in the USA. ${ }^{18,19}$ The explanatory variables entered were patient age and sex (Table 1), clinical characteristics (Table 2), and somatic complications and treatment (Table 3). The CART was set to a maximum of 5 levels for the depth of the tree. The minimum number of cases in each group for the first split was set to 100 . For all nodes after the first split, the minimum number of cases was set to 50 . The objective of dividing into groups is to make the care time within each group as homogeneous as possible. This division continued until the number in each group was below the minimum number of cases or further division no longer showed any statistically significant differences.

The variables used to divide a group into two subgroups (called "dichotomous variables") were selected from the division points within each explanatory variable, such as whether "frequent demands/repetitive complaints" had occurred within the previous 24 hours. In CART, these division points (referred to as "nodes") automatically divide the group into two subgroups so that their statistically significant differences would be greatest ( $P$-value in statistical tests would be smallest). Groups below each node would have all the characteristics of the splits made earlier.
In CART analysis, a series of all terminal nodes represents the case-mix classification system. The terminal node denotes a case-mix group, which has all the characteristics of the splits made earlier. For example, patients in node 10 had not only "frequent demands/repetitive complaints" for "two days or more", but also a length of stay that was less than 105 days and a need for "partial support" or were "totally dependent" in "ADL eating". Statistical analysis of the data was performed using PASW Statistics Version 18 software (SPSS Inc., Chicago, IL, USA).

The study was conducted with the approval of the research ethics committee of the Graduate School of Health Management at Keio University. In the survey, patient names, medical record numbers, and other items that could identify patients were not recorded on the questionnaire.

\section{Results}

\section{Subject background}

The background of the subjects in this study is shown in Table 1. The proportion of subjects aged 65 years or over differed from that in the Data on Mental Health and Welfare, Outline of June 30 Survey in Fiscal Year 2010, ${ }^{7}$ published by the Ministry of Health, Labour and Welfare (hereafter referral to as the "National Daily Census Survey"). Our aim was to cover the full range of patients for the purpose of developing a case-mix grouping system. The proportion of those aged 65 years and over is less in our sample but since the over $65 \mathrm{~s}$ constitute a relatively homogeneous group, we concluded this would not be appropriate.

\section{Distribution of clinical characteristics}

Table 2 shows the distribution of the patients' clinical characteristics. Table 3 shows the presence/absence of complications and medical treatments.

Table I Background of subjects $(n=8,379)$

\begin{tabular}{|c|c|c|}
\hline Characteristic & Present study, n (\%) & $\begin{array}{l}\text { National Daily } \\
\text { Census Survey (\%) }\end{array}$ \\
\hline Men & $4,452(53.1)$ & 49.9 \\
\hline$\geq 65$ years $(n)$ & $2,691(32.1)$ & 49.6 \\
\hline Admission to public sector psychiatric hospitals (n) & $849(10.1)$ & 5.9 \\
\hline Admission to locked wards (n) & $5,217(62.3)$ & 61.9 \\
\hline Involuntary admission (n) & $3,923(46.8)$ & 43.0 \\
\hline \multirow[t]{2}{*}{ With a history of admission (n) } & $6,647(79.8)$ & - \\
\hline & Mean \pm SD & \\
\hline Mean age (years, SD) & $56.7 \pm 14.3$ & - \\
\hline Mean length of stay at time of investigation (day, SD) & $3,242 . I \pm 4,203.3$ & - \\
\hline Mean number of past admissions (n, SD) & $3.3 \pm 1.6$ & - \\
\hline Mean total weighted care time (minutes, SD) & $104.4 \pm 74.2$ & - \\
\hline
\end{tabular}

Abbreviation: SD, standard deviation. 
Table 2 Distribution of clinical characteristics $(n=8,379)$

\begin{tabular}{|c|c|c|c|}
\hline & Mean score & SD & n (proportion) above threshold \\
\hline \multicolumn{4}{|l|}{ Psychiatric symptoms: BPRS (0-6), rated by the physician } \\
\hline Somatic concern & 1.45 & $\mathrm{I} .424$ & I,877 (22.4\%)* \\
\hline Anxiety & 1.63 & 1.352 & $2,020(24.1 \%)^{*}$ \\
\hline Emotional withdrawal & 2.43 & 1.655 & $4,234(50.5 \%)^{*}$ \\
\hline Conceptual disorganization & 2.62 & 1.643 & $4,435(52.9 \%)^{*}$ \\
\hline Hallucinations & 2.08 & 1.763 & $3,501(41.8 \%)^{*}$ \\
\hline Feelings of guilt & 0.51 & 1.004 & $459(5.5 \%)^{*}$ \\
\hline Tension & 1.25 & 1.392 & $1,683(20.1 \%)^{*}$ \\
\hline Mannerisms and posturing & 1.40 & 1.601 & $1,979(23.6 \%)^{*}$ \\
\hline Depressive mood & 0.75 & 1.064 & $632(7.6 \%)^{*}$ \\
\hline Grandiosity & 0.68 & 1.228 & $851(10.2 \%)^{*}$ \\
\hline Hostility & 1.13 & 1.373 & $1,429(17.1 \%)^{*}$ \\
\hline Suspiciousness & 1.49 & 1.496 & $2,114(25.2 \%)^{*}$ \\
\hline Motor retardation & 2.06 & 1.555 & $3,358(40.1 \%)^{*}$ \\
\hline Uncooperativeness & 1.96 & 1.666 & $2,986(35.7 \%)^{*}$ \\
\hline Unusual thought content & 2.66 & 1.696 & $4,686(56.0 \%)^{*}$ \\
\hline Blunted or inappropriate affect & 2.65 & 1.663 & $4,569(54.5 \%)^{*}$ \\
\hline Elation/euphoria & 0.51 & 1.062 & $618(7.4 \%)^{*}$ \\
\hline Psychomotor agitation & 0.75 & 1.268 & $982(11.7 \%)^{*}$ \\
\hline Total BPRS score, $\geq 27$ (n) & - & - & 4,115 (49.2\%) \\
\hline \multicolumn{4}{|l|}{ Cognitive function, rated by nurse } \\
\hline Cognitive ability $(0-3)$ & 0.96 & 0.961 & $2,063(24.6 \%)^{\ddagger}$ \\
\hline Communication ability $(0-3)$ & 0.87 & 0.935 & $2,004(23.9 \%)^{\ddagger}$ \\
\hline Short-term memory impairment (0-I) & 0.33 & 0.470 & $2,748(32.8 \%)^{\S}$ \\
\hline \multicolumn{4}{|l|}{ Problem behavior, rated by nurse } \\
\hline Egocentrism (0-3) & 0.62 & 1.085 & $1,500(19.1 \%)^{\ddagger}$ \\
\hline Frequent demands/repetitive complaints $(0-3)$ & 0.49 & 0.995 & $\mathrm{I}, 28 \mathrm{I}(\mathrm{I} 5.2 \%)^{\ddagger}$ \\
\hline Dependence $(0-3)$ & 0.38 & 0.901 & $992(11.8 \%)^{\ddagger}$ \\
\hline Damage to property $(0-3)$ & 0.02 & 0.200 & $50(0.6 \%)^{\ddagger}$ \\
\hline Resistance to care $(0-3)$ & 0.20 & 0.657 & $530(6.3 \%)^{\ddagger}$ \\
\hline Anorexia $(0-3)$ & 0.07 & 0.400 & $181(2.1 \%)^{\ddagger}$ \\
\hline Resistance to medication $(0-3)$ & 0.07 & 0.372 & $161(2.0 \%)^{\ddagger}$ \\
\hline Verbal abuse $(0-3)$ & 0.25 & 0.737 & $643(7.7 \%)^{\ddagger}$ \\
\hline Wandering behavior $(0-3)$ & 0.22 & 0.732 & $595(8.1 \%)^{\ddagger}$ \\
\hline Water intoxication $(0-3)$ & 0.22 & 0.746 & $599(7.2 \%)^{\ddagger}$ \\
\hline Allotriophagy $(0-3)$ & 0.01 & 0.152 & $28(0.4 \%)^{\ddagger}$ \\
\hline Urination/coprophilia (0-3) & 0.04 & 0.315 & $113(1.3 \%)^{\ddagger}$ \\
\hline Sexual deviation (0-3) & 0.03 & 0.259 & $71(0.8 \%)^{\ddagger}$ \\
\hline Self-injury (during 5 days) $(0-1)$ & 0.02 & 0.132 & $149(1.8 \%)^{\S}$ \\
\hline Suicide attempt (during 5 days) $(0-1)$ & 0.01 & 0.085 & $61(0.7 \%)^{\S}$ \\
\hline Intimidation (during 5 days) $(0-I)$ & 0.09 & 0.290 & $775(9.3 \%)^{\S}$ \\
\hline Actual violence (during 5 days) $(0-I)$ & 0.04 & 0.191 & $319(3.8 \%)^{\S}$ \\
\hline Self-injurious ideation or attempt/violent ideation & 0.73 & 0.788 & $1,243(\mid 4.8 \%)^{\ddagger}$ \\
\hline or violence to others $(0-3)$, rated by the physician & & & \\
\hline \multicolumn{4}{|l|}{ Insight into disease, rated by the physician } \\
\hline Recognition of need for medication $(I-4)$ & 2.11 & 0.490 & $1,469(17.5 \%)^{\pi}$ \\
\hline Consciousness of disease $(I-3)$ & 2.48 & 0.568 & $4,337(51.8 \%)^{\#}$ \\
\hline \multicolumn{4}{|l|}{ ADL dependence $(0-6)$, rated by nurse } \\
\hline Mobility in bed & 0.45 & 1.352 & $700(8.3 \%)^{*}$ \\
\hline Transfer & 0.55 & 1.472 & $816(9.8 \%)^{*}$ \\
\hline Eating & 0.74 & 1.401 & $817(9.7 \%)^{*}$ \\
\hline Toilet use & 0.81 & 1.711 & $1,262(15.1 \%)^{*}$ \\
\hline Personal hygiene & 1.38 & 1.919 & $2,112(25.1 \%)^{*}$ \\
\hline \multicolumn{4}{|l|}{ IADL dependence $(0-2)$, rated by nurse } \\
\hline Meal preparation & 1.36 & 0.78 & $6,791(81.1 \%)^{\S}$ \\
\hline Ordinary housework & 1.39 & 0.74 & $7,096(84.7 \%)^{\S}$ \\
\hline Managing finances & 1.29 & 0.79 & $6,651(79.4 \%)^{\S}$ \\
\hline
\end{tabular}


Table 2 (Continued)

\begin{tabular}{llll}
\hline & Mean score & SD & n (proportion) above threshold \\
\hline Managing medications & 1.38 & 0.74 & $7,069(84.4 \%)^{\S}$ \\
Phone use & 0.84 & 0.87 & $4,423(52.8 \%)^{\S}$ \\
Shopping & 1.04 & 0.84 & $5,597(66.7 \%)^{\S}$ \\
Transportation & 1.21 & 0.84 & $6,154(73.4 \%)^{\S}$ \\
\hline
\end{tabular}

Notes: The threshold was * $\geq 3$ points, $¥ \geq 2$ or 3 points, $\$ \geq 1$ point; "“"insufficient recognition and occasional reluctance or refusal to take medication”; " “little”.

Abbreviations: SD, standard deviation; BPRS, Brief Psychiatric Rating Scale; ADL, activities of daily living; IADL, instrumental activities of daily living.

\section{CART analysis}

The factor that exerted the greatest influence on care time was length of stay (Figure 1). The mean care time was 152 minutes for patients in the short-stay group (length of stay $\leq 104$ days) and 95 minutes in the long-stay group (length of stay $\geq 105$ days). Thus, in general, the care time was shorter in the group that stayed $\geq 105$ days. However, within the long-stay group, the group split by node 6 requiring "partial support" to being "totally dependent" in ADL had a mean care time of 144 minutes and numbered 1,119 were placed in this group. Node 12 was split into node 17 and node 18 by length of stay, and node 18 was split into node 19 and node 20 by verbal abuse. In the group split by node 17 , patients having "frequent demands/ repetitive complaints" for 2 or more days, and a length of stay of 1,532 days or less had a mean "total weighted care time" of 121 minutes. Also, in the group split by node 20, patients having "frequent demands/repetitive complaints" for 2 or more days, length of stay of 1,533 days or more, and "verbal abuse" for 2 or more days had a mean "total weighted care time" of 121 minutes. The first group exceeded, and the latter two groups were very close to, the 125 minutes in the group split by node 14 in the short-stay group which was "independent in ADL eating", had "mild or no psychomotor agitation", and were aged 25 or older.

The overall contribution of rate of variance according to the case-mix classification using CART in this study was $23.4 \%$. If the analysis had been conducted with only length of stay as the variable, this would have explained only $12.7 \%$ of the variance, indicating that case-mix groups should not be developed using only length of stay.

\section{Discussion}

This study is the first to have developed a case-mix grouping system for a large sample of patients with schizophrenia. We found that labor costs, as measured by care time, could be explained by length of stay, patient age, psychomotor agitation, problem behavior manifested by "frequent demands/ repetitive complaints" and "ADL impairment in eating and toileting". Apart from "psychomotor agitation" on the BPRS, patient characteristics could be evaluated by the unit nurse, which should facilitate coding by hospitals.

The first split is by length of stay (number of days) and we note that 105 days is close to the policy goal of discharging within 90 days in acute units. However, there were three groups (nodes 6, 17, and 20) among patients hospitalized for 105 days or more that had a care time close to the mean 152 minutes for patients hospitalized 104 days or fewer (node 1). The first group required more than partial support in toileting (node 6 ; 144 minutes). The second group was independent in toileting but made "frequent demands/repetitive complaints", and were hospitalized for 1,532 days or fewer (node 17;121 minutes). The third group was independent in toileting, made "frequent demands/repetitive complaints", but were hospitalized for 1,533 days or more, and exhibited "verbal abuse" (node 20; 121 minutes). From the perspective of patient care, the fact that the first group requiring support in "toileting" took up so much time indicates that less time would be spent on other patients. This would make it

Table 3 Presence/absence of complications and medical treatments $(n=8,379)$

\begin{tabular}{ll}
\hline Complications, medical treatments, etc & Presence n (\%) \\
\hline Pneumonia & $77(0.9 \%)$ \\
Dehydration & $80(1.0 \%)$ \\
Delirium & $46(0.5 \%)$ \\
Urinary tract infection & $53(0.6 \%)$ \\
Infectious disease isolation & $8(0.1 \%)$ \\
Frequent vomiting & $14(0.2 \%)$ \\
Oxygen therapy & $26(0.3 \%)$ \\
Sputum suction & $15(0.2 \%)$ \\
Ventilator & $1(0.0 \%)$ \\
Tracheotomy/intubation & $2(0.0 \%)$ \\
24-hour infusion & $28(0.3 \%)$ \\
Intravenous hyperalimentation & $14(0.2 \%)$ \\
Percutaneous endoscopic gastrostomy & $85(1.0 \%)$ \\
Frequent blood sugar determination & $98(1.2 \%)$ \\
Pressure ulcer & $64(0.8 \%)$ \\
Wound & $50(0.6 \%)$ \\
Repeated bleeding & $6(0.1 \%)$ \\
Peritoneal lavage & $5(0.1 \%)$ \\
Rehabilitation & $20(0.2 \%)$ \\
Peripheral circulatory disturbance & $2(0.0 \%)$ \\
Hemodialysis & $3(0.0 \%)$ \\
\hline
\end{tabular}




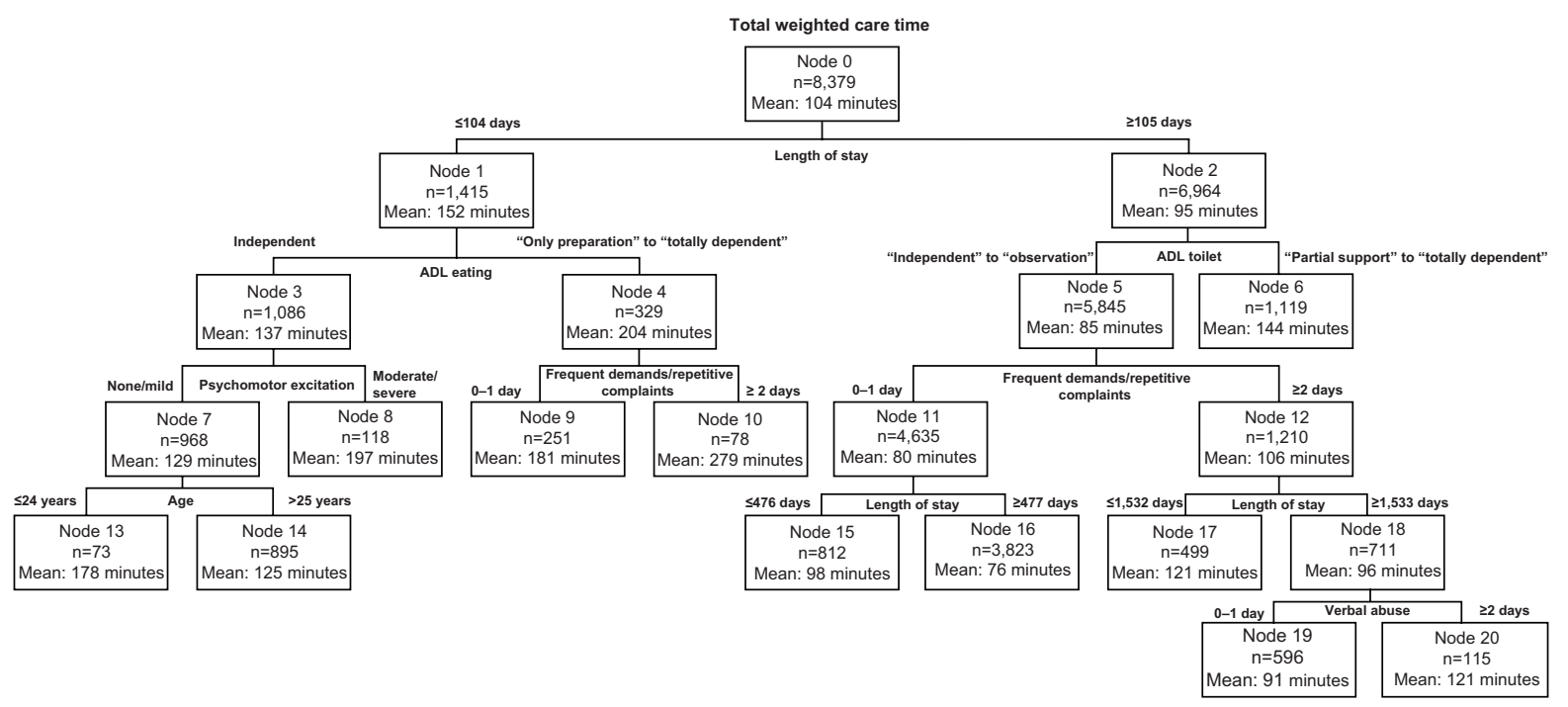

Figure I Results of analysis using Classification And Regression Tree (CART).

Abbreviation: $A D L$, activities of daily living.

difficult to achieve the policy goal of discharging long-stay psychiatric patients because the limited care time in chronic units is focused on patients requiring ADL support. The latter group comprised a significant proportion of patients. Despite the fact that our survey is likely to have undersampled these patients, they still composed $13.4 \%$ of the total group and $16.1 \%$ of the long-stay group.

The first limitation of our study lies in the fact that we did not use facility variables to explain differences in care time. We decided not to do so because short-stay patients would be more likely to be hospitalized in acute care units, while long-stay patients would be mainly in chronic care units. Acute care units would have much higher staffing levels than chronic care units. Moreover, there are many variations in staffing in acute and chronic units, making it difficult to categorize units easily according to their staffing levels. In addition, by categorizing, we might overstandardize and lose the real difference in care time coming from patient characteristics.

The second limitation is that we used "problem behavior" and "insight into disease" items that were developed by a panel of experts from the hospitals we had surveyed. These items have the advantage of being able to be evaluated by nurses, but have not yet been tested for test-retest reliability.

In order to apply our case-mix grouping system for actual payment, further studies must be conducted on direct costs not covered, such as drugs, and overhead costs such as "hotel", administrative, and capital costs. While the overhead costs would not impact on the grouping and relative costs, they would determine the proportion of payment that would be paid across the board for all patients. In addition, the technical details of billing would have to be negotiated with the hospitals. However, designing a case-mix grouping system would be a first step toward a more appropriate payment method.

\section{Acknowledgment}

We sincerely thank the directors and staff of the hospitals surveyed for their cooperation with this study, which was conducted as a part of "Research on the analysis of the actual state of functional differentiation of psychiatric hospitals and the development of methodology" supported by a Fiscal Years 2009 and 2010 Health and Labour Sciences research grant (Research Project on Mental Health Sciences).

\section{Disclosure}

AI, K Yamauchi and NI have received grants from the Japan Pharmaceutical Manufacturer's Association. The other authors report no conflicts of interest in this work.

\section{References}

1. Japan Psychiatric Hospitals Association. [Fiscal Year 2010 Japan Psychiatric Hospitals Association General Survey Report]. Tokyo, Japan: Japan Psychiatric Hospitals Association; 2011. Japanese.

2. Schneider DP, Fries BE, Foley WJ, Desmond M, Gormley WJ. Case mix for nursing home payment: resource utilization groups, version II. Health Care Financ Rev. 1988; Spec No: 39-52.

3. Fries BE, Nerenz DR, Falcon SP, Ashcraft MLF, Lee CZ. A classification system for long-staying psychiatric patients. Med Care. 1990;28: 311-323.

4. Drozd EM, Cromwell J, Gage B, Maier J, Greenwald LM, Goldman HH. Patient case mix classification for Medicare psychiatric prospective payment. Am J Psychiatry. 2006;163:724-732. 
5. Yamauchi K. [Designing a new payment system for psychiatric care: developing of a case-mix classification system]. Byouin kanri (Journal of the Japan Society for Healthcare Administration). 1997;34: 155-167. Japanese.

6. Tamiya N, Noguchi H, Nishi A, et al. Population ageing and wellbeing: lessons from Japan's long-term care insurance policy. Lancet. 2011;378: 1265-1273.

7. Ministry of Health, Labour and Welfare (Mental Health and Disability Health Division, Department of Health and Welfare for Persons with Disabilities, Social Welfare and War Victims' Relief Bureau), National Center of Neurology and Psychiatry (National Institute of Mental Health). [Data on Mental Health and Welfare: Outline of June 30 Survey in Fiscal Year 2010]. Tokyo, Japan: Ministry of Health, Labour and Welfare; 2010. Japanese.

8. Japan Psychiatric Hospitals Association. [Fiscal Year 2007 Japan Psychiatric Hospitals Association General Survey Report]. Tokyo, Japan: Japan Psychiatric Hospitals Association; 2008. Japanese.

9. Sumiyama T, Kitamura T. [BPRS revised edition: subscales, reliability and validity]. Seishinshindangaku (Archives of Psychiatric Diagnostics and Clinical Evaluation). 1995;6:203-218. Japanese.

10. Kitamura T, Machizawa S, Maruyama S, et al. [Test-retest reliability of Oxford University version of the brief psychiatric rating scale (BPRS): a preliminary survey of multicentre collaborative study initiated by the National Institute of Mental Health]. Seishineisei Kenkyu (Journal of Mental Health/National Institute of Mental Health, National Center of Neurology and Psychiatry). 1985;32: 1-15. Japanese.

11. Morris JN, Fries BE, Mehr DR, et al. MDS Cognitive Performance Scale. J Gerontol. 1994;49:M174-M182.
12. Yamauchi K, Ikegami N. [A study on methods for assessing dementia under long-term care insurance: reliability and validity of the Cognitive Performance Scale (CPS)]. Rounenseishin Igaku Zasshi (Japanese Journal of Geriatric Psychiatry). 1999;10: 943-952. Japanese.

13. Morris JN, Murphy K, Nonemaker S, Resident Assessment Instrument, $M D S$ Version 2.1, Japanese version (translation supervised by Ikegami N). Tokyo, Japan: Igaku-Shoin Ltd; 1999. Japanese.

14. Ikegami N, Ikeda S, Takagi Y, et al. [A study on payment systems for long-term care: verification of RUG-III in Japan]. Byouin kanri (Journal of the Japan Society for Healthcare Administration). 1993; 30:181-190. Japanese.

15. Fries BE, Cooney LM Jr. Resource utilization groups. A patient classification system for long-term care. Med Care. 1985;23:110-122.

16. Ministry of Health, Labour and Welfare (Subcommittee on the Comprehensive Assessment of Chronic Hospital Care, the Expert Organization for the Investigation of Remuneration). [Report of the Fiscal Year 2008 Survey on the Comprehensive Assessment of Chronic Hospital Care]. Tokyo, Japan: Ministry of Health, Labour and Welfare; 2009. Japanese.

17. Breiman L, Friedman JH, Olshen R, Stone CJ. Classification and Regression Trees. Belmont, CA, USA: Wadsworth International Group; 1984.

18. Fetter RB, Shin Y, Freeman JL, et al. Casemix definition by diagnosisrelated groups. Med Care. 1980;18(2 Suppl):iii, 1-53.

19. Fries BE, Schneider DP, Foley WJ, Gavazzi M, Burke R, Cornelius E. Refining a case-mix measure for nursing homes: resource utilization groups (RUG-III). Med Care. 1994;32:668-685.
Neuropsychiatric Disease and Treatment

\section{Publish your work in this journal}

Neuropsychiatric Disease and Treatment is an international, peerreviewed journal of clinical therapeutics and pharmacology focusing on concise rapid reporting of clinical or pre-clinical studies on a range of neuropsychiatric and neurological disorders. This journal is indexed on PubMed Central, the 'PsycINFO' database and CAS,

\section{Dovepress}

and is the official journal of The International Neuropsychiatric Association (INA). The manuscript management system is completely online and includes a very quick and fair peer-review system, which is all easy to use. Visit http://www.dovepress.com/testimonials.php to read real quotes from published authors. 